\title{
Gestão de Risco e Cultura de Segurança em Hospital Público
}

\section{Introdução}

A consolidação da cultura de gestão de riscos está diretamente relacionada a notificação de incidentes, uma vez que um dos principais motivos das subnotificações nos serviços de saúde estão relacionados a cultura punitiva, que intimida os colaboradores a notificarem esses incidentes. O aprimoramento da gestão de riscos na instituição e a cultura de notificação de incidentes vêm crescendo exponencialmente nos últimos anos. O hospital investiu no desenvolvimento das lideranças e equipes para a cultura de notificação, não punitiva, focada em melhorias de processos.

\section{Objetivo}

Conhecer os incidentes relacionados a prestação de serviços de saúde para mitigação dos riscos e minimização dos danos.

\section{Metodologia}

A implantação de um sistema de notificação estabeleceu um canal efetivo de comunicação dos incidentes. Várias estratégias foram usadas para o fortalecimento do gerenciamento de risco ao longo dos anos, dentre elas a simplificação do sistema, retirada do campo de identificação do notificante, ações de capacitação para a notificação, uso de ferramentas da qualidade para tratativa dos incidentes, criação do serviço de vigilância de risco, integração com as comissões, entre outros. Aos poucos o entendimento e o conceito de gerenciar seus incidentes foram uniformizados. Os incidentes foram classificados usando a taxonomia da Organização Mundial de Saúde e tratados de acordo com a gravidade. Todos os incidentes recebidos são encaminhados para análise e tratativa responsáveis dos processos e eventos adversos moderados, graves e óbitos com o auxílio do gerenciamento de risco.
Autores: COUTINHO, Claudia Andrea Ceribeli; CARMO, Karina Marques

Série Histórica Anual de Notificações Média/Mês 2010 a 2018

844

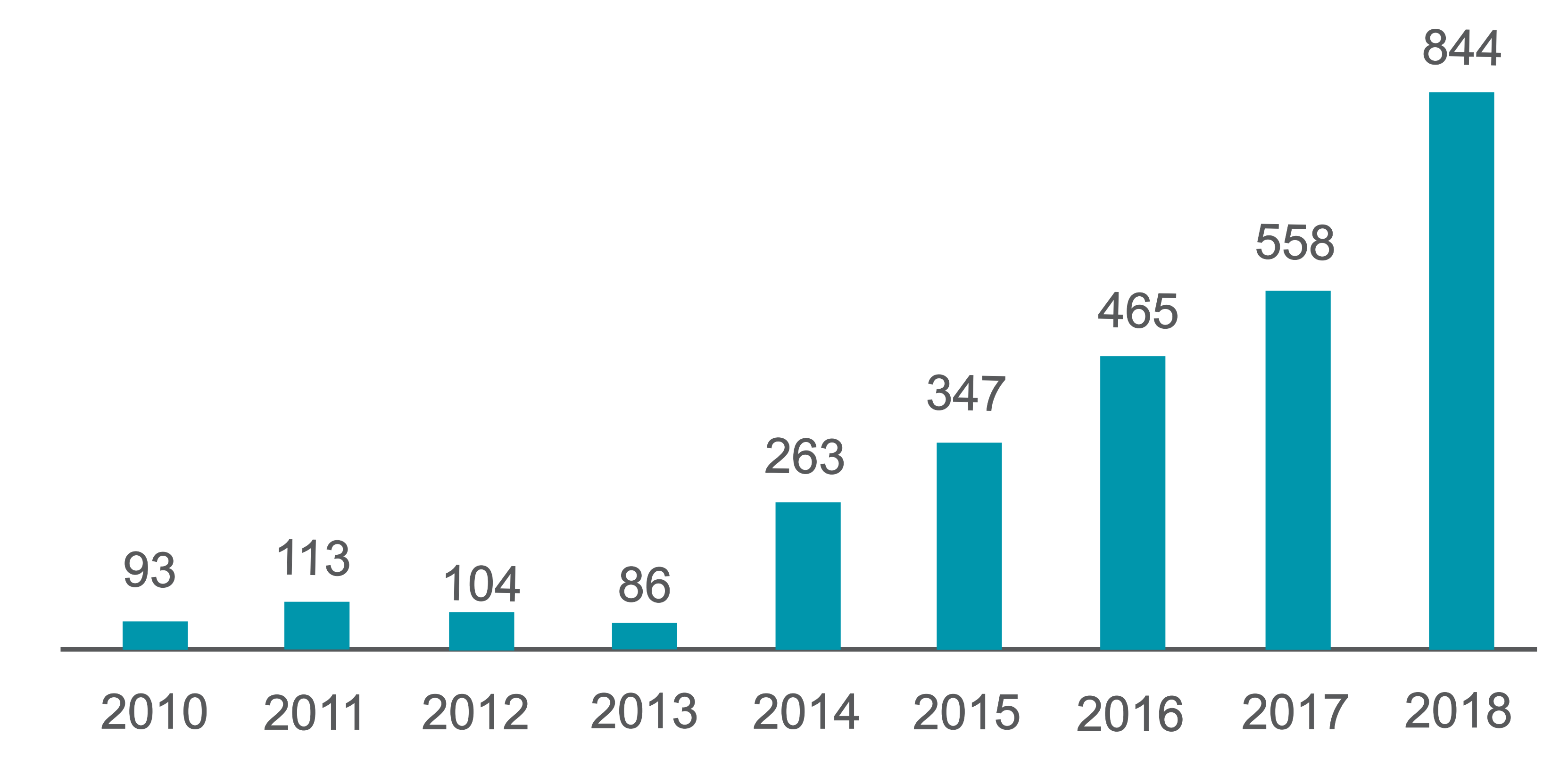

Circunstâncias Reportáveis/Quase-eventos

$x$ Eventos sem danos/Eventos-adversos
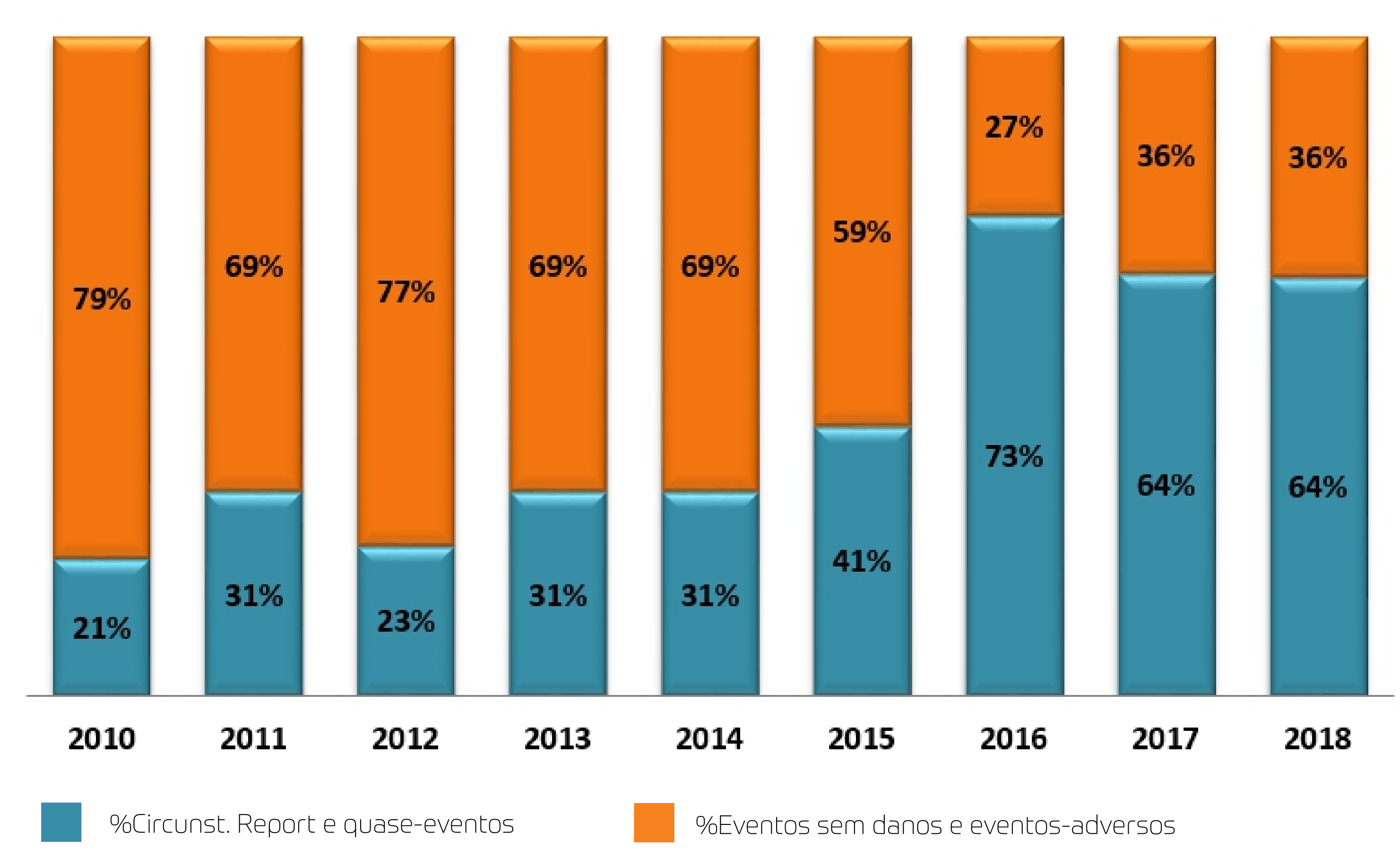

\section{Resultados}

Observa-se o crescimento significativo do número de notificações o que demonstra a maturidade da gestão de risco na instituição conforme gráfico 1.

\section{Conclusão}

Um sistema de notificação simplificado e anônimo, a sensibilização das equipes para notificação de incidentes e uso de ferramentas da qualidade, contribuíram para o aprimoramento do gerenciamento dos incidentes, possibilitando a priorização, análise e propostas de ações de mitigação dos mesmos e fortaleceram a cultura de segurança na instituição, minimizando erros. 